\title{
Desain Fast Displacement Ship untuk Lomba Kapal Cepat pada HYDROCONTEST
}

\author{
Pieter Mario Fernandez, Wasis Dwi Aryawan, dan Gita Marina Ahadyanti \\ Departemen Teknik Perkapalan, Fakultas Teknologi Kelautan, Institut Teknologi Sepuluh Nopember (ITS) \\ e-mail:wasis@na.its.ac.id
}

\begin{abstract}
Abstrak-HYDROCONTEST merupakan perlombaan kapal cepat dan efisien antar mahasiswa di tingkat internasional dalam format race menggunakan kapal yang didesain, diteliti, dan diproduksi sendiri oleh para mahasiswa. Perlombaan ini mendorong para peserta untuk berinovasi dalam menghasilkan kapal dengan performa keseluruhan yang baik dari segi hambatan, propulsi, maneuvering, dan efisinesi sistem elektrik. Melihat iklim riset dalam perlombaan dan berdasarkan pengalaman/keikutsertaan tim HYDRONE ITS dalam HYDROCONTEST 2017, dilakukan proses desain kapal yang akan digunakan tim HYDRONE ITS dalam HYDROCONTEST 2018 dimana dalam proses desain ini juga dilakukan analisa $C F D$ pada 3 variasi bentuk haluan kapal dan optimisasi sistem propulsi (pitch propeller dan $\mathbf{R P M}$ ) agar kapal memiliki kecepatan dan endurance yang optimal. Dari proses penelitian ini, diperoleh desain kapal monohull dengan haluan berupa axe bow dengan estimasi kecepatan maksimal $5.25 \mathrm{~m} / \mathrm{s}$ dan jumlah jarak tempuh maksimum 24 lap lintasan tanpa mengisi ulang baterai.
\end{abstract}

Kata Kunci-Kapal Cepat, Hambatan, CFD, Propulsi, Optimisasi.

\section{PENDAHULUAN}

$\mathrm{H}$ YDROCONTEST merupakan perlombaan kapal cepat dan efisien antar mahasiswa di tingkat internasional yang diadakan sejak tahun 2014 dan diikuti oleh puluhan tim mahasiswa dari belasan negara. Adapun tujuan utama dari perlombaan ini adalah untuk mengajak para pelajar turut berpartisipasi dalam mengembangkan inovasi yang dapat diterapkan pada dunia perkapalan. Format perlombaan yang diadakan oleh HYDROS Foundation ini berupa race menggunakan kapal yang didesain, diteliti, dan diproduksi sendiri oleh para mahasiswa. Konsep dan desain kapal yang digunakan oleh setiap peserta adalah sebebas-bebasnya selama tidak melebihi batasan ukuran maksimal serta menggunakan baterai dan motor penggerak yang disediakan penyelenggara perlombaan.

Perlombaan ini pertama kali diikuti oleh tim HYDRONE ITS pada tahun 2017 dengan menggunakan kapal berupa displacement catamaran untuk mengikuti kategori perlombaan Lightweight Race dan Long-Distance Race serta kapal trimaran untuk mengikuti kategori perlombaan Heavyweight Race. Peringkat yang diperoleh pada saat itu (dari 23 tim) adalah peringkat 10 untuk kategori Lightweight Race, peringkat 14 untuk kategori Heavyweight Race, dan peringkat 15 untuk kategori Long-Distance Race. Kegagalan sistem elektrik dan kebocoran kapal dilaporkan sebagai kendala utama tim selama perlombaan berlangsung [1].

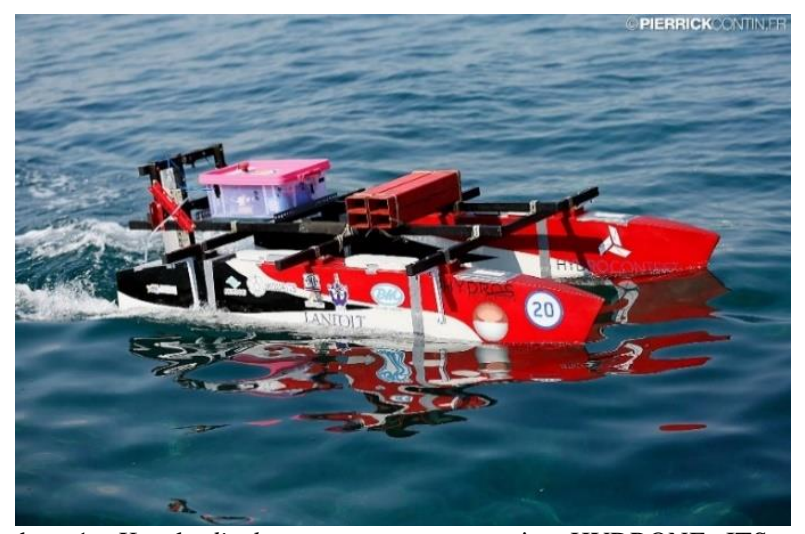

Gambar 1. Kapal displacement catamaran tim HYDRONE ITS pada HYDROCONTEST 2017.

Berdasarkan pengalaman pada keikutsertaan tersebut, terdapat banyak evaluasi dan rencana pengembangan agar tim dapat bersaing dengan performa yang lebih baik di keikutsertaan berikutnya. Evaluasi dan rencana pengembangan ini meliputi pengembangan desain lambung kapal yang lebih efisien, peningkatan efisiensi sistem propulsi, perbaikan sistem steering gear agar kapal memiliki maneuvering yang lebih baik, peningkatan kualitas produksi kapal, serta perbaikan sistem elektrik. Melihat banyaknya aspek yang harus dikembangkan oleh tim serta manfaat dari perlombaan HYDROCONTEST sendiri, penulis merasa bahwa event ini dapat menjadi sarana untuk mengembangkan desain kapal yang efisien, melakukan penelitian, serta turut berkontribusi dalam pengembangan tim HYDRONE ITS (penulis masih merupakan bagian dari tim saat Jurnal ini dibuat).

Dalam jurnal ini, akan didesain kapal yang akan digunakan untuk kategori perlombaan Lightweight Race dan LongDistance Race (satu kapal untuk dua kategori perlombaan) yang akan digunakan tim HYDRONE ITS pada HYDROCONTEST 2018. Dalam pengerjaan jurnal ini, terus dilakukan komunikasi antara penulis dan tim HYDRONE ITS untuk menghasilkan desain kapal dengan performa yang optimal dan memastikan adanya sinergi antara proses desain dan proses produksi mengingat keduanya dilakukan secara beriringan.

\section{TINJAUAN PUSTAKA}

\section{A. Peraturan Perlombaan}

Perlombaan dibagi menjadi tiga kategori perlombaan yaitu Lightweight Race, Heavyweight Race, dan Long-Distance Race. Setiap tim diperbolehkan membuat maksimal 2 kapal untuk mengikuti ketiga kategori tersebut. Dalam jurnal ini, kapal yang didesain akan digunakan untuk kategori Lightweight 
Race dan Long-Distance Race. Kedua kategori ini dibedakan pada objektif perlombaan dan panjang lintasannya seperti yang dapat dilihat pada

Tabel 1. Tidak ada batasan terkait desain kapal selain ukuran maksimal kapal. Dalam perlombaan ini, setiap tim akan menggunakan motor (1400 Watt) dan baterai yang sama yang telah disediakan panitia.

\section{B. Data Hasil Perlombaan Pada HYDROCONTEST 2017}

Berdasarkan data yang dikumpulkan tim HYDRONE ITS pada HYDROCONTEST 2017, kapal tercepat dalam kategori Lightweight-Race memiliki waktu tercepat sekitar 45 detik untuk menyelesaikan lintasan sepanjang 600 meter (kecepatan rata-rata sekitar $4.5 \mathrm{~m} / \mathrm{s}$ ) sementara jumlah lap terbanyak yang ditempuh adalah 22 lap untuk panjang lintasan 400 meter.

Tipe kapal yang berada di peringkat 4 besar kedua kategori ini terdiri dari kapal hydrofoil, displacement monohull, dan displacement catamaran seperti yang dapat dilihat pada Tabel 2 dan

Tabel 3

Tabel 1.

Perbandingan Kategori Perlombaan

\begin{tabular}{cll}
\hline \hline \multirow{2}{*}{ Aspek } & \multicolumn{2}{c}{ Kategori Perlombaan } \\
\cline { 2 - 3 } & \multicolumn{1}{c}{ Lightweight Race } & \multicolumn{1}{c}{ Long-Distance Race } \\
\hline \multirow{3}{*}{ Objektif } & $\begin{array}{l}\text { Kapal menyelesaikan } \\
\text { lintasan dengan waktu } \\
\text { tercepat. }\end{array}$ & $\begin{array}{l}\text { Kapal menempuh lintasan } \\
\text { dalam waktu 60 menit dengan } \\
\text { jumlah lap terbanyak tanpa } \\
\text { mengisi ulang baterai }\end{array}$ \\
Muatan & $\begin{array}{l}\text { Dua buah balok beban (masing-masing } 10 \mathrm{~kg} \text { ). } \\
\text { Panjang }\end{array}$ & Setiap balok beban berukuran $50 \mathrm{~cm} \times 12 \mathrm{~cm} \mathrm{x} 10 \mathrm{~cm}$. \\
Lintasan & $600 \mathrm{~m}$ & $400 \mathrm{~m}$ \\
\hline \hline
\end{tabular}

Tabel 2.

Tipe kapal pada peringkat 4 besar kategori Lightweight Race.

\begin{tabular}{cccc}
\hline \hline Peringkat & Nama Tim & Negara & Tipe Kapal \\
\hline 1 & HEIA-FR & Swiss & Hydrofoiled Trimaran \\
2 & Belgrade & Serbia & Displacement Monohull \\
3 & HEIG-VD & Swiss & Hydrofoiled Monohull \\
4 & Athens & Yunani & Displacement Monohull \\
\hline \hline
\end{tabular}

Tabel 3.

Tipe kapal pada peringkat 4 besar kategori Long-distance Race.

\begin{tabular}{cccc}
\hline \hline Peringkat & Nama Tim & Negara & Tipe Kapal \\
\hline 1 & Hydrometra & Kolombia & Displacement Catamaran \\
2 & Southampton & UK & Displacement Monohull \\
3 & HEIA-FR & Swiss & Displacement Monohull \\
4 & Belgrade & Serbia & Displacement Monohull \\
\hline \hline
\end{tabular}

C. Evaluasi Kapal Pada HYDROCONTEST 2017

1) Berat Kapal

Kapal memiliki lambung yang terlalu berat sehingga LWT kapal mencapai $28 \mathrm{~kg}$, padahal berat kapal akan berpengaruh pada length-displacement ratio yang akan berpengaruh pada hambatan kapal [2].

2) Bentuk Haluan dan Buritan

Bentuk haluan hanya mengikuti bentuk haluan konvensional dan tidak didesain khusus untuk mengurangi hambatan. Kapal juga memiliki sarat yang terlalu tinggi pada bagian transom sehingga terjadi turbulensi di belakang transom [3].

3) Trim

Akibat posisi thrust line propeller cukup jauh di bawah titik berat kapal, kapal mengalami trim saat propeller menghasilkan thrust. Trim berpengaruh pada hambatan kapal [4] dan efisiensi sistem propulsi [5].

\section{4) Sistem Propulsi}

Tidak dilakukan optimisasi sistem propulsi sehingga kapal cukup cepat kehabisan daya.

5) Navigasi

Kapal tidak dilengkapi dengan sistem FPV (First Person View) sehingga driver kesulitan menavigasi kapal saat posisi kapal jauh dari driver.

\section{METODOLOGI}

Metodologi desain kapal dapat dilihat pada diagram alir (Gambar 2).

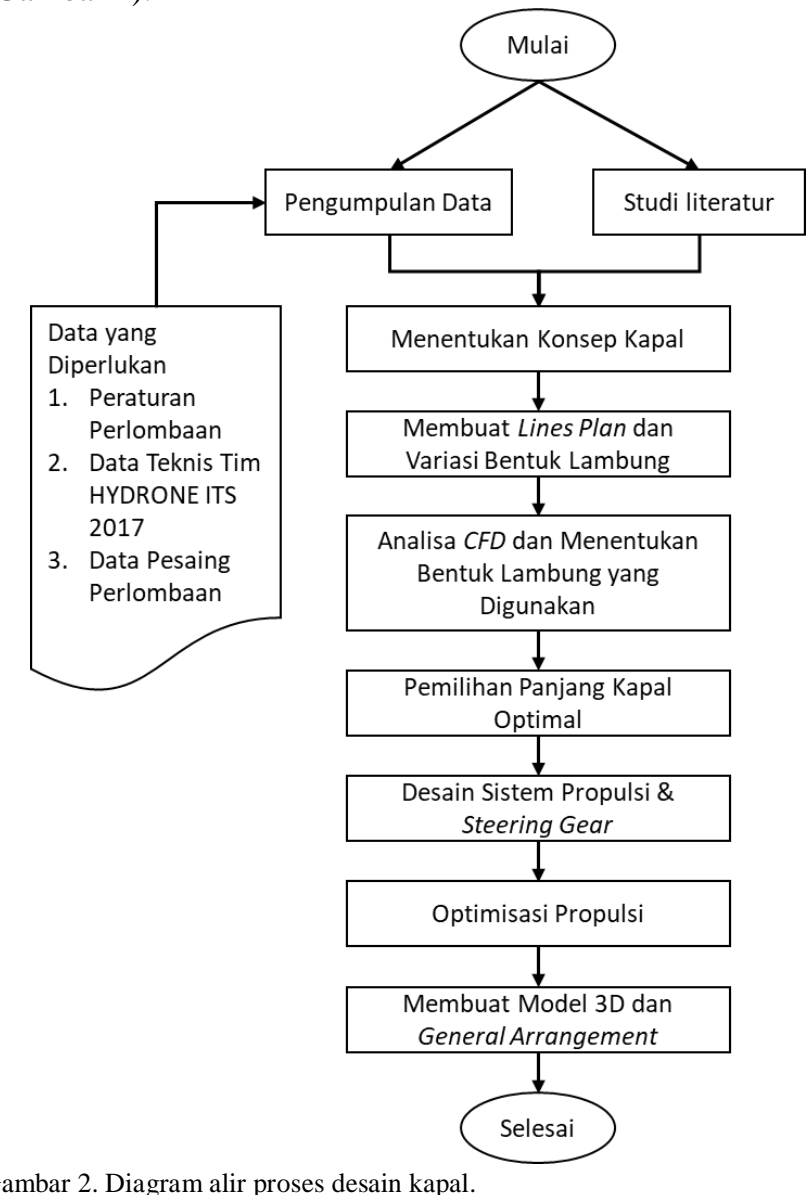

\section{ANALISA TEKNIS}

\section{A. Menentukan Konsep Kapal}

Penentuan konsep kapal dilakukan dengan melihat tipe kapal pada hasil perlombaan di tahun sebelumnya. Dikarenakan kapal akan digunakan pada dua kategori sekaligus, maka konsep kapal yang digunakan adalah displacement monohull melihat tipe kapal tersebut cukup mendominasi baik pada peringkat teratas kategori Lightweight Race dan Long-Distance Race (

\section{Tabel 3).} Tabel 2 dan

\section{B. Desain dan Variasi Bentuk Lambung Kapal}

Model awal kapal mereferensi pada seri MARIN Fast Displacement Hull Form [6] dimana kapal merupakan slender monohull dengan round bilge dan transom stern. Kapal didesain memiliki sarat yang kecil pada bagian transom agar tidak terjadi turbulensi pada aliran air di belakang kapal. Kapal tidak memiliki parallel middle body untuk memaksimalkan length of enterance dan length of run sehingga dapat mereduksi wave making resistance [7]. Bentuk sisi lambung kapal di atas permukaan air dibuat lurus atau tidak melengkung pada arah transversal untuk memudahkan proses produksi. Dalam jurnal ini 
dibuat tiga variasi model dengan bentuk haluan yang berbeda-beda, yaitu conventional bow, vertical bow, dan axe bow. Perbandingan ukuran utama

Tabel 4 . pada ketiga variasi model dapat dilihat pada

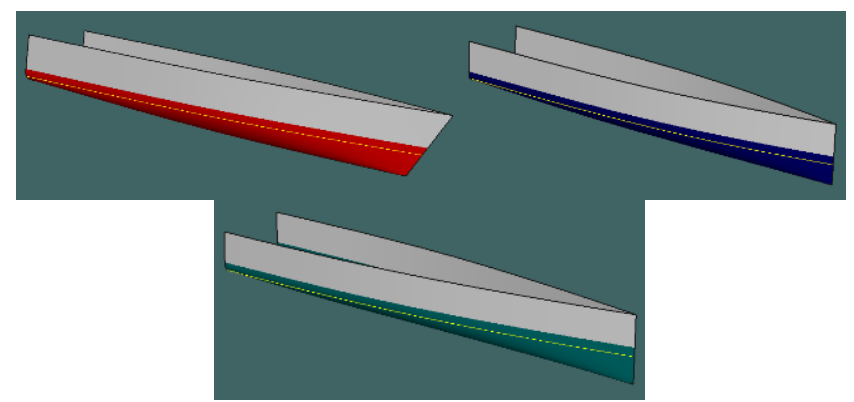

Gambar 3. Variasi model lambung kapaL dengan conventional bow (kiri atas), vertical bow (kanan atas), dan axe bow (bawah).

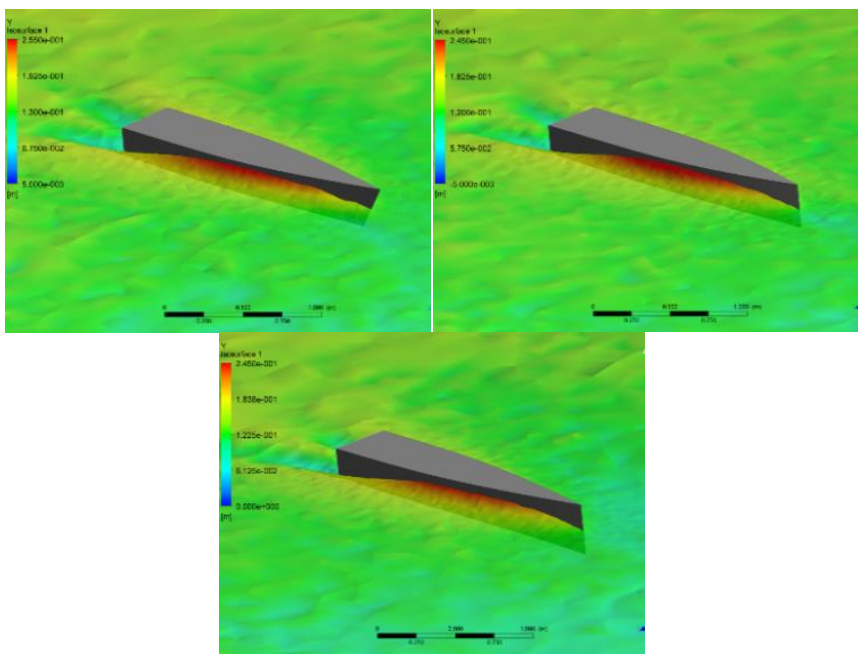

Gambar 4. Visualisasi gelombang yang dihasilkan kapal pada model conventional bow (kiri atas), vertical bow (kanan atas), dan axe bow (bawah).

Tabel 4.

Ukuran utama variasi model.

\begin{tabular}{cccc}
\hline \hline & Conventional Bow & Vertical Bow & Axe Bow \\
\hline LOA & $2.20 \mathrm{~m}$ & $2.20 \mathrm{~m}$ & $2.20 \mathrm{~m}$ \\
LWL & $2.07 \mathrm{~m}$ & $2.20 \mathrm{~m}$ & $2.20 \mathrm{~m}$ \\
$\mathrm{~B}$ & $0.4 \mathrm{~m}$ & $0.4 \mathrm{~m}$ & $0.4 \mathrm{~m}$ \\
$\mathrm{~T}$ & $0.105 \mathrm{~cm}$ & $0.1 \mathrm{~cm}$ & $0.135 \mathrm{~cm}$ \\
$\mathrm{H}$ & $0.3 \mathrm{~m}$ & $0.3 \mathrm{~m}$ & $0.335 \mathrm{~m}$ \\
$\mathrm{Cb}$ & 0.418 & 0.419 & 0.316 \\
Disp. & $36 \mathrm{~kg}$ & $36 \mathrm{~kg}$ & $36 \mathrm{~kg}$ \\
\hline \hline
\end{tabular}

\section{Analisa CFD}

Untuk memilih desain lambung yang akan digunakan dari ketiga variasi model yang telah dibuat, dilakukan analisa $C F D$ untuk membandingkan besar hambatan lambung kapal. Perbandingan hambatan tidak menggunakan rumus pendekatan dikarenakan ketiga model memiliki ukuran utama dan koefisien yang hampir serupa. Selain untuk membandingkan hambatan kapal, lewat analisa $C F D$ juga dapat dilakukan visualisasi gelombang dan aliran fluida di sekitar lambung kapal yang dapat berguna untuk pengambilan keputusan desain selanjutnya seperti modifikasi bentuk lambung dan pemosisian propeller. Dari analisa ini, didapati bahwa model axe bow memiliki hambatan terkecil dibanding dua variasi model lainnya. Beberapa penelitian terdahulu juga menyebutkan modifikasi haluan dari bentuk konvensional menjadi axe bow mengakibatkan pengurangan hambatan kapal dan peningkatan seakeeping [8][9].

Tabel 5.

Perbandingan hambatan variasi model.

\begin{tabular}{ccccc}
\hline \hline $\begin{array}{c}\text { Speed } \\
(\mathrm{m} / \mathrm{s})\end{array}$ & Fn & $\begin{array}{c}\text { Conventional Bow } \\
\text { Resistance }(N)\end{array}$ & $\begin{array}{c}\text { Vertical Bow } \\
\text { Resistance }(N)\end{array}$ & $\begin{array}{c}\text { Axe Bow } \\
\text { Resistance }(N)\end{array}$ \\
\hline 0 & 0.00 & 0 & 0 & 0 \\
2.5 & 0.54 & 37.31 & 37.20 & 32.29 \\
5 & 1.08 & 72.33 & 65.10 & 64.81 \\
7.5 & 1.61 & 124.36 & 118.84 & 110.55 \\
\hline \hline
\end{tabular}

\section{Pemilihan Panjang Kapal yang Optimal}

Setelah mendapatkan bentuk lambung yang memiliki hambatan terkecil dari hasil analisa $C F D$, dibuat variasi panjang kapal untuk dianalisa hambatannya dengan hipotesa bahwa kapal yang lebih panjang dengan DWT yang sama cenderung memiliki hambatan yang lebih kecil [10]. Model divariasikan menjadi 3 varian dengan panjang 1.9 meter $(-30 \mathrm{~cm}$ dari desain awal), 2.2 meter $(+0 \mathrm{~cm}$ dari desain awal), dan 2.5 meter $(+30$ $\mathrm{cm}$ dari desain awal). Sarat dari tiap model mengikuti displacement masing-masing yang sedikit berbeda dari desain awal karena perubahan luas surface lambung yang berdampak pada perubahan berat lambung.

Hasil analisa hambatan menunjukkan bahwa model kapal yang lebih panjang memiliki hambatan yang lebih kecil. Meskipun demikian, penambahan panjang dari ukuran awal (2.2 meter menjadi 2.5 meter) hanya berdampak pada pengurangan hambatan yang tidak begitu signifikan sehingga panjang yang digunakan tetap 2.2 meter agar kapal memiliki dimensi yang minimal dan memudahkan proses pengiriman kapal ke lokasi perlombaan.

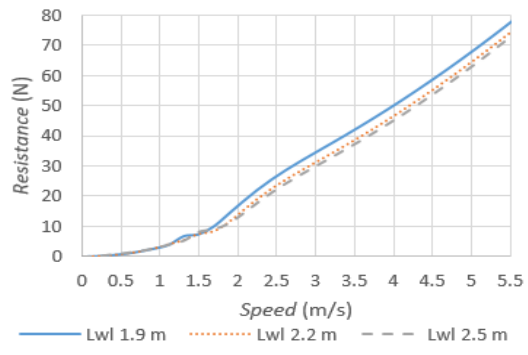

Gambar 5. Perbandingan hambatan model dengan variasi panjang.

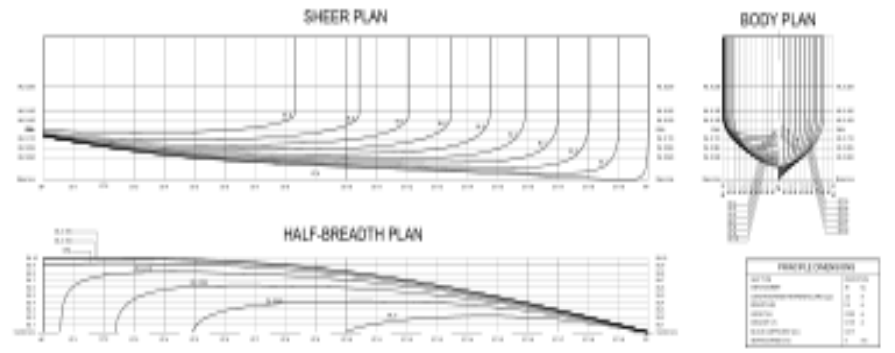

Gambar 6. Lines plan kapal.

\section{E. Desain Sistem Propulsi}

Sistem propulsi yang digunakan pada desain kapal ini merupakan podded azimuth propulsion dimana pod dapat berotasi pada sumbu vertikal untuk mengubah arah thrust dan membelokkan kapal tanpa menggunakan kemudi. Meskipun demikian, penyangga pod yang berbentuk foil juga dapat berfungsi sebagai kemudi saat kapal meluncur tanpa 
menghasilkan thrust. Kapal dengan sistem azimuth propulsion memiliki kemampuan maneuvering yang lebih baik dibanding sistem fixed propulsion dan kemudi [11].

Kecepatan aliran air di sekitar lambung kapal pada arah memanjang dapat divisualisasikan dengan simulasi $C F D$ agar propeller dapat diposisikan dimana kecepatan aliran air maksimum (di luar daerah wake) sehingga tidak menyebabkan penurunan efisiensi propeller [12]. Aliran air dengan kecepatan sama dengan kecepatan kapal (Vs) diindikasikan dengan warna biru tua sementara warna lainnya (di bawah permukaan air) mengindikasikan perlambatan kecepatan fluida akibat interaksi fluida dengan lambung kapal (Gambar 7). Propeller tidak diposisikan lebih jauh ke bawah karena dapat menyebabkan kapal mengalami trim saat propeller menghasilkan thrust.

Salah satu fitur unggulan dari desain kapal ini adalah sistem pendinginan komponen elektrik tanpa menggunakan pompa sehingga dapat menghemat pemakaian listrik yang akan berpengaruh pada endurance kapal dalam Long-Distance Race. Dengan memanfaatkan prinsip Bernoulli, air akan masuk melalui inlet yang terletak di sisi bawah lambung kapal ketika kapal mulai bergerak, mendinginkan sistem, dan keluar melalui outlet di transom kapal. Tidak dibutuhkan kecepatan yang tinggi agar sistem ini dapat bekerja karena bagian tertinggi dari sistem berdekatan dengan permukaan air (sistem memiliki head yang kecil).

\section{F. Optimisasi Propulsi}

Propulsi merupakan salah satu faktor yang sangat berpengaruh pada performa kapal dalam perlombaan. Optimisasi propulsi dilakukan untuk menentukan pitch propeller dan RPM motor agar kapal memiliki kecepatan maksimum pada Lightweight Race dan memiliki endurance maksimum pada Long-Distance Race.

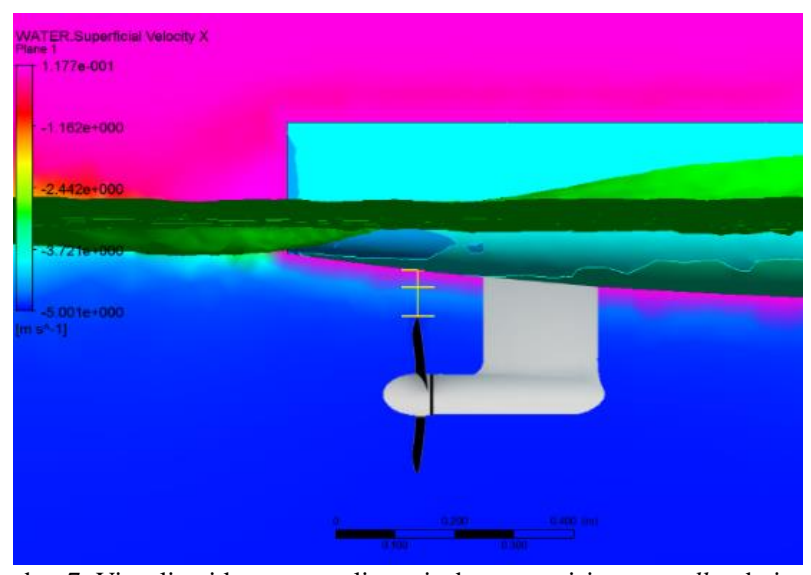

Gambar 7. Visualisasi kecepatan aliran air dan pemosisian propeller dari tampak samping.

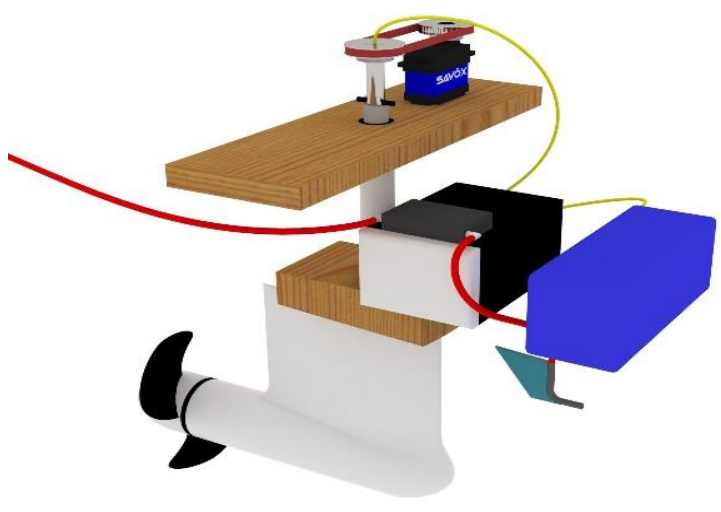

Gambar 8. Desain sistem propulsi.

Optimisasi yang dilakukan merupakan Optimisasi Global dengan metode Exhaustive Search pada 3 variasi pitch dan pengujian pada RPM 0 - 3000 menggunakan data open water test propeller yang diolah bersama data hambatan kapal dari analisa $C F D$. Terdapat sedikit keterbatasan dalam proses optimisasi ini dikarenakan data open water test (grafik KT, KQ, dan J) yang diperoleh tidak meliputi bentuk grafik secara menyeluruh atau hanya pada range $\mathrm{J}$ tertentu saja.

Berdasarkan hasil optimisasi, dengan pitch dan RPM yang optimum, kapal akan memiliki kecepatan maksimum $5.25 \mathrm{~m} / \mathrm{s}$ pada Lightweight Race dan endurance 24 lap pada LongDistance Race (Gambar 9 dan Gambar 10).

\section{G. Model 3D}

Pembuatan Model 3D dilakukan tidak hanya untuk visualisasi kapal melainkan juga untuk menentukan pemosisian komponen kapal dan untuk perhitungan titik berat. Model 3D juga dapat diproyeksi menjadi gambar 2 dimensi sehingga mempermudah proses pembuatan general arrangement.

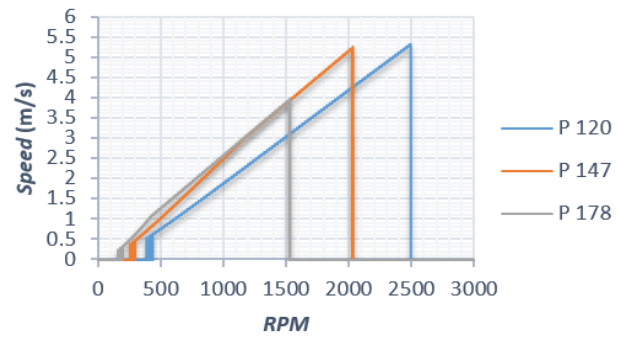

Gambar 9. Pengaruh RPM propeller terhadap kecepatan kapal pada 3 variasi pitch propeller.

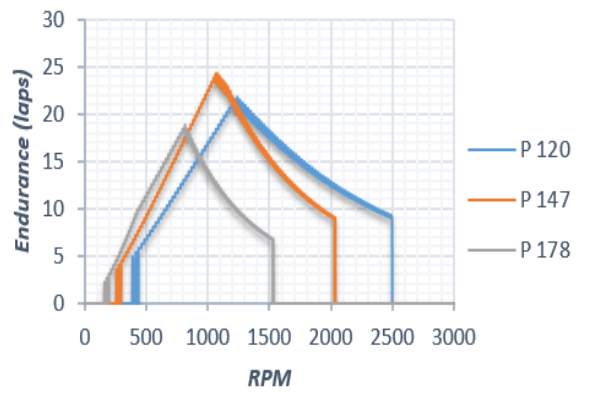

Gambar 10. Pengaruh RPM propeller terhadap jumlah lap yang dapat ditempuh kapal pada 3 variasi pitch propeller. 


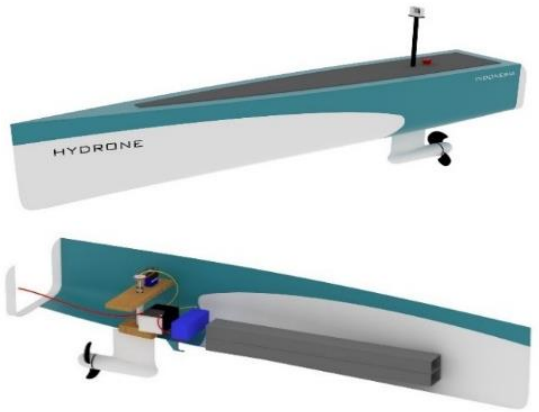

Gambar 11. Model 3D

\section{H. Stabilitas}

Kapal didesain memiliki titik berat serendah mungkin dengan cara memosiskan beban dan komponen elektrik di titik terendah kapal (Gambar 11) dengan harapan kapal akan memiliki stabilitas yang baik. Meskipun dimensi lambung kapal cukup tinggi, berat lambung hanya sekitar $17 \%$ dari displacement sehingga kapal justru memiliki nilai GZ yang besar pada sudut heel yang ekstrim. Kurva GZ kapal (Gambar 12) menunjukkan kapal memiliki GZ maksimum pada sudut heel 99 derajat. Pengecekan pada lambung kapal yang telah diproduksi mennjukkan kapal kembali ke posisi upright dengan cukup cepat setelah dimiringkan pada berbagai sudut heel (Gambar 13).

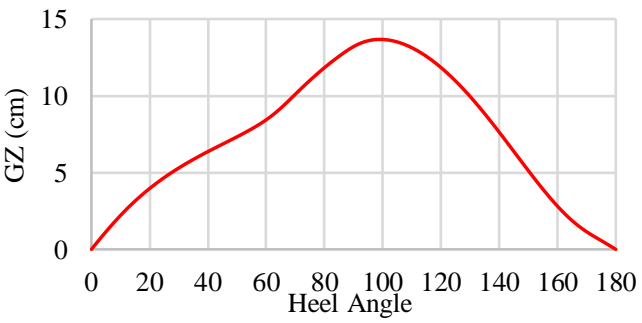

Gambar 12. Kurva GZ kapal.

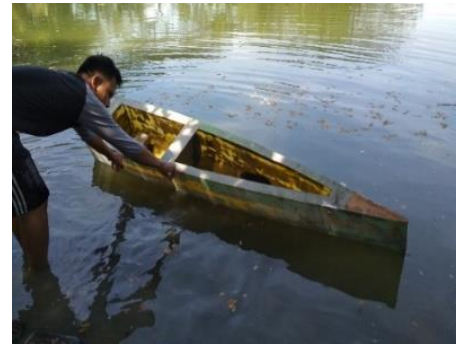

Gambar 13. Pengecekan kebocoran dan pengujian stabilitas kapal.

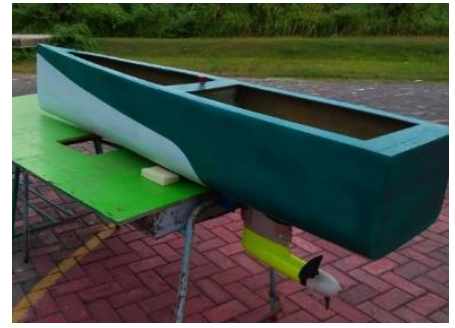

Gambar 14. Kapal dalam proses produksi.

\section{Produksi Kapal}

Kapal diproduksi oleh tim HYDRONE ITS untuk dilombakan pada HYDROCONTEST 2018. Berat kapal diperkirakan akan sesuai atau lebih ringan dari berat desain (16 $\mathrm{kg}$ ). Belum sempat dilakukan trial saat jurnal ini dibuat namun belum terdapat kendala dalam proses produksi sehingga kapal sesuai dengan desain.

\section{KESIMPULAN}

Berdasarkan proses desain kapal ini, maka kesimpulan yang dapat diambil adalah:

1. Dihasilkan desain fast displacement ship dengan tipe slender monohull.

2. Berdasarkan hasil simulasi $C F D$, varian lambung kapal dengan bentuk haluan berupa axe bow memiliki hambatan terkecil dibanding conventional bow dan vertical bow.

3. Tanpa mengubah payload, lebar, dan tinggi kapal, semakin panjang kapal maka kapal akan cenderung memiliki hambatan total yang lebih kecil.

4. Sistem propulsi merupakan podded azimuth propulsion dengan strut penyangga pod yang juga dapat berfungsi sebagai kemudi saat propeller sedang tidak menghasilkan thrust. Kapal tidak menggunakan pompa untuk sistem pendinginan komponen elektrik untuk menghemat penggunaan listrik saat Long-Distance Race.

5. Berdasarkan hasil optimisasi pitch propeller dan RPM motor, kapal dapat mencapai kecepatan maksimum 5.25 $\mathrm{m} / \mathrm{s}$ dalam Lightweight Race dan menempuh 24 lap dalam Long-Distance Race.

6. Kapal memiliki stabilitas yang baik karena memiliki dimensi lambung yang cukup tinggi namun titik berat yang sangat rendah.

7. Kapal diproduksi oleh tim HYDRONE ITS untuk dilombakan dalam HYDROCONTEST 2018. Belum ada kendala mayor selama proses produksi dan kapal sesuai dengan desain yang dibuat.

\section{DAFTAR PUSTAKA}

[1] HYDRONE ITS, "Laporan Pertanggungjawaban Batharasurya Hydrone ITS: HYDROCONTEST 2017,” Surabaya, 2017.

[2] A. Molland, J. Wellicome, and P. Couser, "Resistance Experiments on A Systematic Series of High Speed Displacement Catamarans Forms: Variation of Length-Displacement Ratio and BreadthDraught Ratio," Southampton, 1994.

[3] M. Haase, J. Binns, G. Thomas, and N. Bose, "Wave-piercing Catamaran Transom Stern Ventilation Process.” 2015.

[4] F. D. Luca and C. Pensa, "The Naples Warped Hard Chine Hulls Systematic Series," Naples, Italy, 2017.

[5] M. Islam, B. Veitch, A. Akinturk, N. Bose, and P. Liu, "Experiments with Podded Propulsors in Static Azimuthing Conditions," 2007.

[6] MARIN, "The MARIN Systematic Series Fast Displacement Hulls."

[7] A. Papanikolaou, Ship Design: Methodologies of Preliminary Design. Springer, 2014.

[8] J. Keuning, S. Toxopeus, and J. Pinkster, "The Effect of Bowshape on the Seakeeping Performance of a Fast Monohull," 1997.

[9] R. Dahna, "Analisis Alternatif Hull Form Self-Propelled Barge Untuk Meningkatkan Performa Hidrodinamika," Surabaya, 2018.

[10] J. Keuning and J. Pinkster, "Optimisation of the seakeeping behaviour of a fast monohull," in ProceedIngs of the Third International Conference on Fast Sea TransportatIon, 1995.

[11] R. Pakaste, "Experience with Azipod Propulsion Systems on Board Marine Vessels," ABB Rev., 1999.

[12] H. Sid'qon, "Kajian Bentuk Stern Hull Kapal Shallow Draft Untuk Meningkatkan Performance Kapal," Surabaya, 2015. 